This document is the accepted manuscript version of the following article:

Wäckerlin, C., Gallardo, A., Mairena, A., Baljozovic, M., Cahlík, A., Antalík, A., ... Ernst, K. H. (2020). On-surface hydrogenation of buckybowls: from curved aromatic molecules to planar non-Kekulé aromatic hydrocarbons. ACS Nano.

https://doi .org/10.1021/acsnano.0c04488

\title{
On-Surface Hydrogenation of Buckybowls: From Curved Aromatic Molecules to Planar Non-Kekulé Aromatic Hydrocarbons
}

Christian Wäckerlin ${ }^{\dagger \neq}$, Aurelio Gallardo ${ }^{\ddagger}$, , Anaïs Mairena ${ }^{\dagger},{\text { Miloš Baljozović }{ }^{\dagger}, \text { Aleš Cahlík } k^{\ddagger}, l}$, Andrej Antalík ${ }^{\perp}$, Jiří Brabec ${ }^{\perp}$, Libor Veis ${ }^{\perp}$, Dana Nachtigallová\#, Pavel Jelínek ${ }^{\ddagger}$, and Karl-Heinz Ernst ${ }^{\dagger}, \neq, \nabla,{ }^{*}$

+ Surface Science and Coating Technologies, Empa, Swiss Federal Laboratories for Materials Science and Technology, Überlandstrasse 129, 8600 Dübendorf, Switzerland

₹ Institute of Physics of the Czech Academy of Sciences, Cukrovarnická 10, 16200 Praha 6, Czech Republic $\S$ Faculty of Mathematics and Physics, Charles University, V Holešovičkách 2, 18000 Praha, Czech Republic \| Faculty of Nuclear Sciences and Physical Engineering, Czech Technical University in Prague, Břehová 78/7, 115 19 Praha 1, Czech Republic

$\perp$ J. Heyrovský Institute of Physical Chemistry, Academy of Sciences of the Czech Republic, v.v.i. Dolejškova 3, 18223 Praha 8, Czech Republic

\# Institute of Organic Chemistry and Biochemistry, Academy of Sciences of the Czech Republic, v.v.i., Flemingovo nam. 2, 16610 Praha 6, Czech Republic

$\nabla$ Institute of Physics of the Czech Academy of Sciences, Cukrovarnická 10, 16200 Praha 6, Czech Republic

ABSTRACT: Functionalization of surfaces with derivatives of Buckminsterfullerene fragment molecules seems a promising approach towards bottom up fabrication of carbon nanotube modified electrode surfaces. The modification of a $\mathrm{Cu}(100)$ surface with molecules of the buckybowl pentaindenocorannulene has been studied by means of scanning tunneling microscopy, carbon monoxide-modified non-contact atomic force microscopy, time-of-flight secondary mass spectrometry and quantum chemical calculations. Two different adsorbate modes are identified, in which the majority is oriented such that the bowl cavity points away from the surface and the convex side is partially immersed into a fouratom vacancy in the $\mathrm{Cu}(100)$ surface. A minority is oriented such that the convex side points away from the surface with the five benzo tabs oriented basically parallel to the surface. Thermal annealing leads to hydrogenation and planarization of the molecules in two steps under specific $\mathrm{C}-\mathrm{C}$ bond cleavage. The benzo tabs of the convex side up species serve as hydrogen source. The final product has an open shell electron structure that is quenched on the surface.

KEYWORDS buckybowls; scanning probe microscopy; open-shell aromatic hydrocarbons; density functional theory; onsurface chemistry

On-surface chemistry of polyaromatic hydrocarbons (PAHs) has become an important bottom-up approach towards large polymeric structures for functional interfaces that are not available by classical solution chemistry. ${ }^{1-3}$ Graphene nanoribbons and macrocycles, for example, have been synthesized after deposition of polyaromatic precursors followed by thermally-induced C-C coupling reactions. ${ }^{4,5}$ Dehalogenation and cyclodehydrogenation are thereby the most important steps of surface-based $\mathrm{C}-\mathrm{C}$ coupling chemistry nowadays. ${ }^{6-8}$ Cyclodehydrogenation, in general, is the usual thermally-induced pathway of sterically overcrowded polyaromatic compounds at surfaces. ${ }^{9-12}$ Even carbon nanotubes (CNTs) can be obtained in such process..$^{13}$ On the other hand, hydrogenation of curved carbon sheets, such as Buckminsterfullerene $\left(C_{60}\right)$ leads to unzipping into planar PAHs only at high temperatures and hydrogen pressure. ${ }^{14,15}$

Buckminsterfullerene fragment molecules, so called buckybowls, ${ }^{16,17}$ are promising interface modifier molecules, because they have outstanding electronic properties. Besides a pronounced blue-light electroluminescence, ${ }^{18}$ corannulene $\left(\mathrm{COR}, \mathrm{C}_{20} \mathrm{H}_{10}\right.$, Fig. $\left.\mathrm{la}\right)$ and its derivatives show a prominent electron acceptance from alkali metals. ${ }^{19-21}$ Confined to metal surfaces, buckybowls show interesting 2D crystallization phenomena, such as pentagonal tiling and symmetry mismatch, ${ }^{22-28}$ non-covalent concave complexation, ${ }^{29,30}$ as well as reversible, entropy-driven phase transitions. . $^{31,32}$ 
a

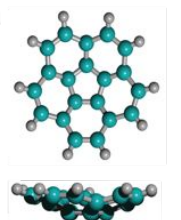

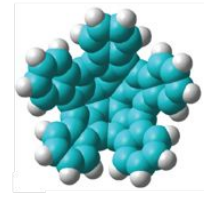

Figure 1. (a) Top and side views onto ball-and-stick models of corannulene (COR). (b) Structure and full-space model of penta-indenocorannulene (PIC).

Adsorption of buckybowls leads to substantial Pauli repulsion on metal surfaces. ${ }^{33,34}$ The high electron density at the convex bowl side causes a push-back of metal electrons into the substrate, which, in turn, leads to a substantial interface dipole moment without any charge transfer. COR engages in a tilted configuration on $\mathrm{Cu}(111) .^{31}$ Tilted adsorbate modes have also been observed for monoindenoCOR and terphenyICOR on $\mathrm{Cu}(111){ }^{35,36}$ So far, only the isolated $C_{70}$ fragment bowl $\mathrm{C}_{38} \mathrm{H}_{14}$ engaged with the bowl axis aligned normal to the surface, but became tilted upon intermolecular interactions. ${ }^{37}$ As origin of tilted configuration of isolated buckybowls, special binding configurations to the surface, e.g., C6 rings over hollow sites, maximization of van der Waals contact and minimization of Pauli repulsion has been discussed. ${ }^{38}$

In order to achieve a defined surface functionalization with CNT caps, the buckybowl pentaindenocorannulene ${ }^{39-44}$ (PIC, Fig. 1b) seems the logical choice. Its cyclodehydrogenation should yield a $\mathrm{C}_{50} \mathrm{H}_{10}$ entity that could become upon further dehydrogenation a standing CNT. ${ }^{45,46}$ Motivated by such possibility, the interaction of PIC with a $\mathrm{Cu}(100)$ surface has been studied by means of scanning tunneling microscopy (STM), scanning force microscopy (AFM) as well as dispersion-enabled density functional theory (DDFT) and density matrix renormalization group (DMRG) calculations. A major fraction of isolated PIC molecules stands 'bowl-cavity-up' at low-temperatures. PIC is thereby partly submerged into the surface by creating a four-atom vacancy underneath the pentagonal center ring. A minority fraction stands convex side-up, pointing with the pentagonal centered $C 5$ ring away from the surface.

\section{Scheme 1. PIC and its hydrogenation products $\mathrm{PIC} /+\{2,4\} \mathrm{H}$}

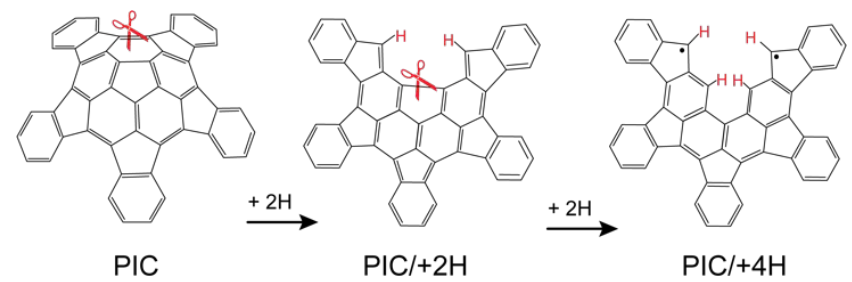

Instead of cyclodehydrogenation upon thermal treatment, a vast majority of PIC becomes hydrogenated and C-C bond cleavage occurs at the corannulene core in two steps (Scheme 1). Both reaction products are planar and are clearly identified by time-of-flight secondary ion mass spectrometry (ToF-SIMS) and carbon monoxide-tipmodified AFM (CO-nc-AFM). By theoretical means it is evaluated if the hydrogenated products have open shell character.

\section{RESULTS AND DISCUSSION}

Figure 2 shows ST micrographs of PIC on $\mathrm{Cu}(100)$ at $5 \mathrm{~K}$. The molecules $\left(\sim 8 \times 10^{-3}\right.$ molecules $\left./ \mathrm{nm}^{2}\right)$ were deposited at $330 \mathrm{~K}$ prior to cooling. Most of the molecules appear with 5 protrusions, suggesting that the 5 benzo tabs are pointing away from the surface (cavity-up configuration). A minority is imaged as one bright protrusion surrounded by 5 shallow features. Such appearance is expected for a configuration in which the PIC cavity is facing the surface (cavity-down configuration). These two configurations are observed for isolated molecules. As previously observed for the $\mathrm{C}_{38} \mathrm{H}_{14}$ bowl, ${ }^{37}$ tilted configurations can occur due to intermolecular interactions when two or more molecules aggregate.

The cavity-up configuration is experimentally the most commonly observed adsorbate mode here. Constant height nc-AFM images with a CO-modified tip of cavityup and cavity-down PIC (Figure 3), in combination with force spectroscopy (Figure S1 and Table S3), allows determination of the height of parts of the species above the surface. The images are compared with AFM simulations using the particle probe method. ${ }^{47,48}$ For the cavity-up adsorbate, the simulated STM and AFM images reproduce well the experimental contrasts (Figure S2). However, the experimental height of the 5 benzo tabs was only achieved in the simulation when a $2 \times 2$ atom vacancy in the topmost $\mathrm{Cu}(100)$ surface layer was considered under the molecule (Figure 4a,b). Experimental and theoretical heights of the of the indeno group ends agree with such configuration within a 20 pm error (Table S3). 


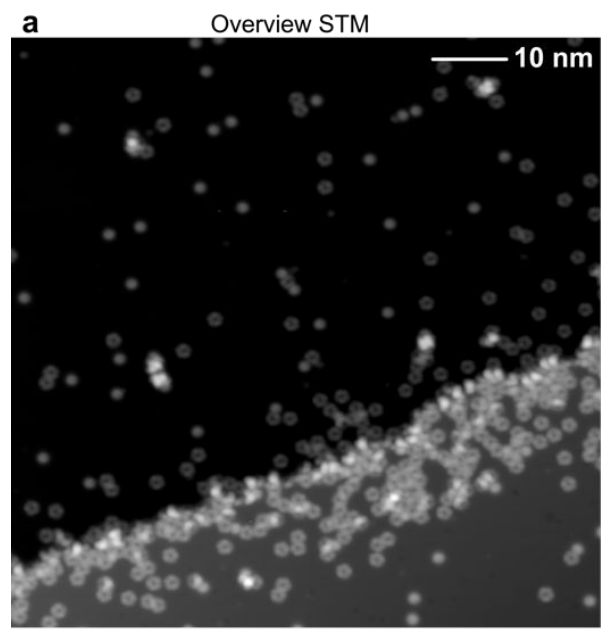

b

C STM w/CO tip
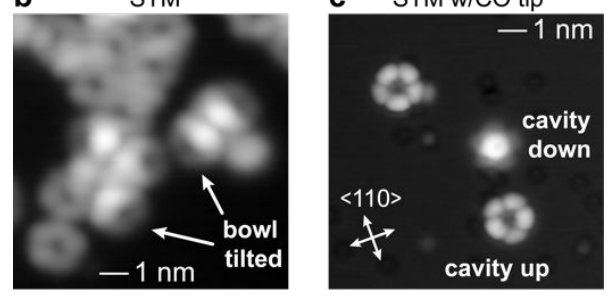

Figure 2. STM images of PIC recorded at $5 \mathrm{~K}$ after deposition on $\mathrm{Cu}(100)$ at $330 \mathrm{~K}$ (STM imaging parameters are listed in Table S1). (a) Overview image $\left(100 \times 100 \mathrm{~nm}^{2}\right)$. (b) STM image $\left(10 \times 10 \mathrm{~nm}^{2}\right)$ showing tilted species due to intermolecular interaction. (c) STM image with CO-modified tip $(10 \times 10$ $\mathrm{nm}^{2}$ ). Most molecules adsorb such that the cavity points away from the surface (cavity-up). A cavity-down configuration is also indicated.
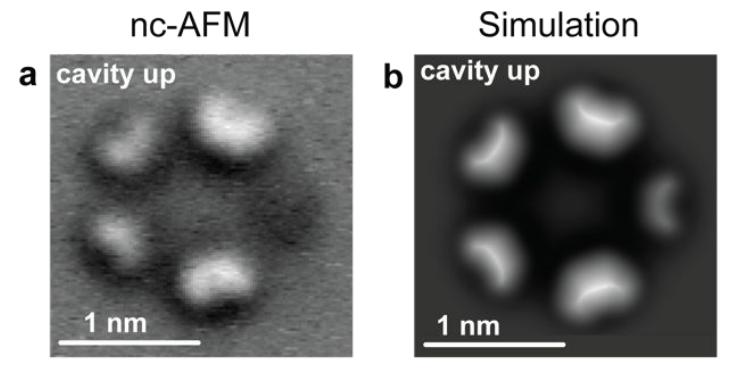

C
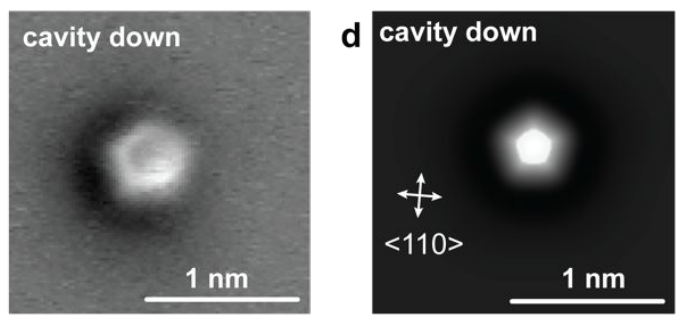

Figure 3. Experimental and simulated CO-nc-AFM images of PIC in cavity pointing up $(a, b)$ and cavity pointing down $(c, d)$ orientation. The $\mathrm{Cu}(100)$ substrate orientation as indicated in (d) applies to all images. 


\section{Surface \\ Modification \\ Pentaindenocorannulene}

The observation of a cavity-up configuration is not supported by previous DFT calculations, which did not consider vacancies in the surface. ${ }^{38}$ Relaxation starting from a cavity-up adsorption mode leads to tilted configurations with maximal van der Waals (vdW) contact to the surface and presumably smaller Pauli repulsion (Table S2). ${ }^{35,38}$ Nevertheless, Note that for $\mathrm{C}_{60}$ on $\mathrm{Cu}(100)$ multiple-atom vacancies, leading to a reconstructed stripe phase, has been observed, ${ }^{49}$ and $\mathrm{C}_{60}$-induced vacancies were also observed on $\mathrm{Cu}(111)$ and Pt surfaces. ${ }^{50,51}$ Adsorption on a 4-adatom cluster or the presence of 8 surrounding adatoms also yields a stable cavity-up configuration in DFT (Table S2), but these structures strongly disagree with the AFM height results (Figure S1 and Table S3). In the case of PIC taking the cavity-down configuration, constant height nc-AFM leads to an image in which only the central 5-ring is observed. The corresponding particle probe modelling reproduces well AFM contrast and height (Figure 3, S1 and Table S4).

Buckybowls may reshape a $\mathrm{Cu}(110)$ surface at step edges. $^{52}$ But how can a PIC molecule create a four-atom vacancy? In particular on $\mathrm{Cu}(100)$ vacancies are known to be originated at step edges and diffuse into the surface with an activation barrier almost as low as for single adatoms diffusion. ${ }^{53,54}$ Being initially pinned to such vacancy, a PIC molecule may then either cause three surface atoms adjacent to the vacancy to become adatoms on the terrace or 3 more diffusing vacancies will get pinned under the PIC once they arrive there. Another scenario is initial formation of an entire four-atom vacancy that become then occupied by PIC. Figure 2a shows that there are much more cavity-up bowls near the step edge on the upper terrace than on the lower terrace or further away from step edges. Such observation agrees well with the proposed mechanism of vacancy formation at a step edge, followed by vacancy diffusion into the upper terrace. ${ }^{53,54}$ Finally, it has been shown that Cu metal islands on $\mathrm{Cu}(100)$ display a dynamic system until certain island size is reached.$^{55}$ It is therefore also possible that the stepedges diffuse around the pre-adsorbed PIC molecules, trapping them in 4-atom vacancies. a
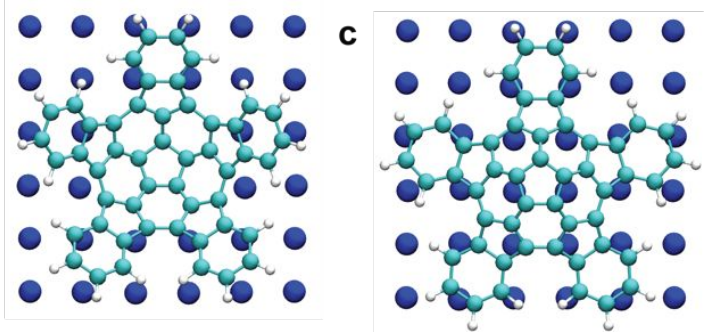

b
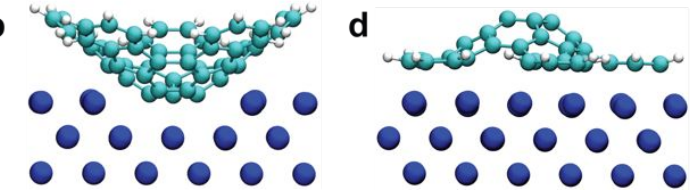

Figure 4. Top and side views of fully relaxed DFT models of PIC on $\mathrm{Cu}(100)$ in the cavity-up $(a, b)$ and cavity-down adsorbate mode $(c, d)$. Four substrate atoms of the top layer are missing under the molecule in the cavity-up mode. For clarity $\mathrm{Cu}$ atoms of the two lowest slab layers (a) or of the top layer (b) have in part been omitted.

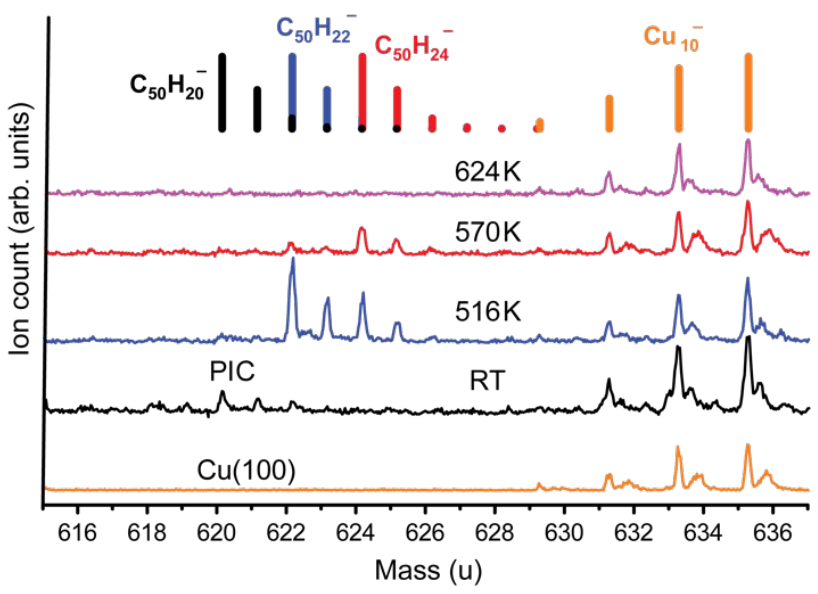

Figure 5. ToF-SIM spectra acquired from $\mathrm{Cu}(100)$ covered with $\sim 3 \times 10^{-2} \mathrm{PIC}$ molecules $/ \mathrm{nm}^{2}$. The expected mass distributions of PIC $\left(\mathrm{C}_{50} \mathrm{H}_{20}{ }^{-}\right), \mathrm{PIC} /+2 \mathrm{H}\left(\mathrm{C}_{50} \mathrm{H}_{22}{ }^{-}\right), \mathrm{PIC} /+4 \mathrm{H}$ $\left(\mathrm{C}_{50} \mathrm{H}_{24}{ }^{-}\right)$and $\mathrm{Cu}\left(\mathrm{Cu}_{10}{ }^{-}\right)$are shown as colored bars. Annealing to $516 \mathrm{~K}$ induces the formation of hydrogenated $\mathrm{PIC} /+2 \mathrm{H}$ and $\mathrm{PIC} /+4 \mathrm{H}$ species and the disappearance of the PIC $\left(\mathrm{C}_{50} \mathrm{H}_{20}{ }^{-}\right)$signal. 

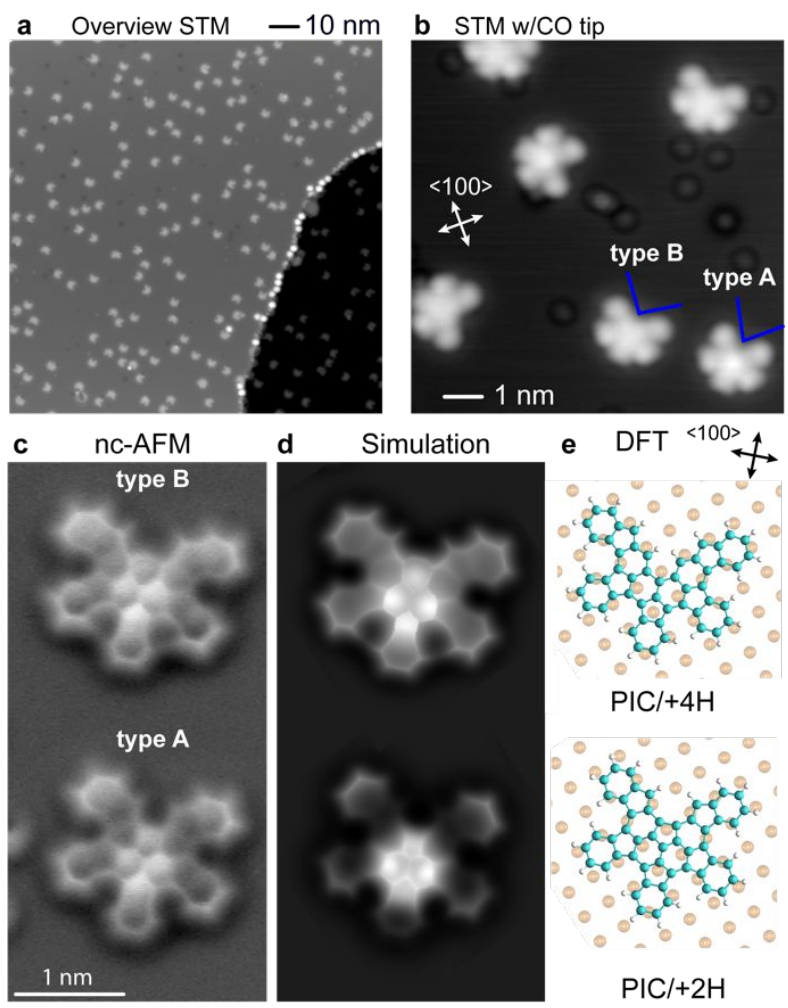

Figure 6. STM $(a, b)$ and CO-nc-AFM images (c) of $\mathrm{PIC} / \mathrm{Cu}(100)$ after annealing to $490 \mathrm{~K}$. The images were recorded at $5 \mathrm{~K}$, imaging parameters are documented in Table S1. (a) Overview STM image $\left(80 \times 80 \mathrm{~nm}^{2}\right)$ Most molecules appear to be planar. (b) Classification into two different types based on different opening angles (indicated by blue lines). (c) CO-nc-AFM of an area containing both species. (d) AFM image simulation of both types based on DFT models shown in (e). (e) DFT models of adsorbed $\mathrm{PIC} /+2 \mathrm{H}$ and $\mathrm{PIC} /+4 \mathrm{H}$, assuming hydrogenation under $\mathrm{C}-\mathrm{C}$ bond cleavage at one corannulene $\mathrm{C} 6$ ring (type $\mathbf{A}$ ), and in a second step hydrogenation under $\mathrm{C}-\mathrm{C}$ bond cleavage at the C5 center ring (type B).

\section{Planarization \\ Chemistry \\ Pentaindenocorannulene}

of

The temperature-induced surface chemistry of PIC on $\mathrm{Cu}(100)$ is well studied by means of ToF-SIMS, a method analyzing the mass of adsorbates after bombardment with primary ions or ion clusters. Figure 5 shows anion ToF-SIM spectra of about $3 \times 10^{-2}$ molecules $/ \mathrm{nm}^{2}$ with increasing temperature. After deposition of PIC onto the substrate kept at room temperature, the signal at $620.2 \mathrm{u}$ and its characteristic isotope pattern is identified as the PIC molecular anion $\mathrm{C}_{50} \mathrm{H}_{20}{ }^{-}$. After annealing to $516 \mathrm{~K}$, fragments such as $\mathrm{C}_{50} \mathrm{H}_{22}{ }^{-}(622.2 \mathrm{u})$ and $\mathrm{C}_{50} \mathrm{H}_{24}{ }^{-}(624.2 \mathrm{u})$ are detected, corresponding to doubly $(\mathrm{PIC} /+2 \mathrm{H})$ and quadruplicate $(\mathrm{PIC} /+4 \mathrm{H})$ hydrogenated PIC. Annealing to $570 \mathrm{~K}$ still shows $\mathrm{PIC} /+4 \mathrm{H}$ signals (at smaller intensity due to non-specific decomposition), but much more decreased signals for $\mathrm{PIC} /+2 \mathrm{H}$. After annealing to $623 \mathrm{~K}$ all PIC-derived signals disappear.
The corresponding cation ToF-SIMS data (Figure S3) and SIM spectra acquired at lower coverage $\left(\sim 10^{-2}\right.$ molecules $/ \mathrm{nm}^{2}$, Figure S4) also show the two hydrogenation steps $(\mathrm{PIC} /+\{2,4\} \mathrm{H})$. The fact that the intensity of carbon ( $\mathrm{C}^{-}$ions) is not significantly decreased (Table S5) shows that the disappearance of PIC-derived signals after annealing to $624 \mathrm{~K}$ is due to non-specific C$C$ coupling and fragmentation rather than desorption. These processes yield randomly linked carbon aggregates and ultimately (at higher temperatures) graphene. ${ }^{56}$

STM images of PIC/Cu(100) acquired after annealing to $490 \mathrm{~K}$ show that the PIC has been transformed into planar entities (Figure 6). As in case of pristine PIC, these species appear with 5-lobes, but with a larger distance between two of them. Based on the angle spanned by these two lobes, two different planar species (types $\mathbf{A}$ and $\mathbf{B}$ ) are actually identified (Figure 6b). High resolution CO-nc-AFM images of these two types are shown in Figure 6c. Simulation of AFM images has been performed based on DFT modelling of $\mathrm{PIC} /+2 \mathrm{H}$ and $\mathrm{PIC} /+4 \mathrm{H}$ species (Figures $6 \mathrm{~d}, \mathrm{e})$. Excellent agreement in AFM contrast and height (Figure S1 and Table S6) is achieved by $\mathrm{C}-\mathrm{C}$ bond cleavage at the corannulene core (Scheme 1). That is, in the first step $\mathrm{C}-\mathrm{C}$ bond cleavage occurs on a core $\mathrm{C} 6$ ring, followed by $\mathrm{C}-\mathrm{C}$ bond cleavage of the center $\mathrm{C} 5$ ring. Consequently, type $\mathbf{A}$ corresponds to $\mathrm{PIC} /+2 \mathrm{H}$ and type $\mathbf{B}$ corresponds to $\mathrm{PIC} /+4 \mathrm{H}$.

AFM images show that the wider opening angle of species $\mathbf{B}$ is because the central 5-ring has been opened (Figure S5). Thus, the alternative reaction product where $\mathrm{C}_{50} \mathrm{H}_{24}$ (i.e. $\mathrm{PIC} /+4 \mathrm{H}$ ) is obtained by cutting the first $\mathrm{C}-\mathrm{C}$ bond but then doubly hydrogenating both carbon atoms $\left(\mathrm{sp}^{2}\right.$ $\rightarrow \mathrm{sp}^{3}$ ) must be excluded. Furthermore, it is noteworthy that abundance of type $\mathbf{B}$ molecules (wider cut) increases with increasing temperature at the expense of type $\mathbf{A}$ molecules (Table 1 ), consistent with the increasing relative intensity of $\mathrm{PIC} /+4 \mathrm{H}$ with respect to $\mathrm{PIC} /+2 \mathrm{H}$ (Figure 5).

Table 1. Abundance of planarized molecules*

\begin{tabular}{|c|c|c|}
\hline $\begin{array}{c}\text { Annealing } \\
\text { temperature }\end{array}$ & $\begin{array}{c}\text { type } \mathbf{A} \\
\mathbf{P I C} / \mathbf{+ 2} \mathbf{H}\end{array}$ & $\begin{array}{c}\text { type } \mathbf{B} \\
\mathbf{P I C} / \mathbf{+ 4} \mathbf{H}\end{array}$ \\
\hline $490 \mathrm{~K}$ & $55 \pm 3 \%$ & $34 \pm 2 \%$ \\
\hline $543 \mathrm{~K}$ & $19 \pm 2 \%$ & $72 \pm 3 \%$ \\
\hline
\end{tabular}

* For counts and STM obtained after annealing to $543 \mathrm{~K}$ see Table S7 and Figure S6.

A planar entity is favored in energy due to the larger surface contact area over a curved carbon bowl. As mechanism, however, the $\mathrm{C}-\mathrm{C}$ bonds either open after hydrogen adatoms are added to the molecule or a $\mathrm{Cu}$ adatom acts as catalyst and opens the $\mathrm{C}-\mathrm{C}$ bond by forming a metalorganic intermediate. Such intermediate is known to play a role in the reverse step, the C-C bond formation in the Ullmann coupling reaction. ${ }^{29,30}$ Although 
temperature-dependent reversibility has been concluded for the debromination step of the Ullmann reaction, ${ }^{57}$ to our knowledge is was not observed so far for the demetallization prior to $\mathrm{C}-\mathrm{C}$ bond formation.

What remains to be discussed is the origin of hydrogen leading to the formation of $\mathrm{PIC} /+\{2,4\} \mathrm{H}$. The possible sources are either the residual hydrogen gas in the vacuum chamber or hydrogen transfer from other molecules that have become dehydrogenated. It has been shown in the case of nickel that hydrogenation of adsorbed molecules may occur by subsurface hydrogen, ${ }^{58}$ a mechanism that has not been observed for copper under ultrahigh vacuum conditions. As control experiment, ToF-SIMS measurements have been performed after annealing a $\mathrm{PIC} / \mathrm{Cu}(100)$ sample in presence of $\mathrm{D}_{2}$ gas $\left(2 \times 10^{-7} \mathrm{mbar}\right), \mathrm{D}_{2} \mathrm{O}$ vapor and coadsorbed dekadeuteriumacenaphtene (Figure $\mathrm{S} 6$ ). For the $D_{2}$ and $D_{2} \mathrm{O}$ experiments, no signal at the mass of $\mathrm{PIC} /+4 \mathrm{D}$ is detected. Rather, the SIM spectra are consistent with formation of $\mathrm{PIC} /+\{2,4\} \mathrm{H}$, which means that deuterium from the gas phase is not involved. This result excludes residual hydrogen in the vacuum chamber, which is present at a partial pressure below $1 \times 10^{-10} \mathrm{mbar}$, as source of hydrogenation. With coadsorbed dekadeuteriumacenaphtene $\left(\mathrm{C}_{12} \mathrm{D}_{10}\right)$ as deuterium source, however, deuterated PIC is observed. Consequently, the hydrogen originates from other PIC molecules. It was not possible to clearly identify specific mass signals corresponding to dehydrogenation products of PIC. This could be due to an unspecific dehydrogenation mechanism or due to a very low ionization probability of the respective dehydrogenation products. Moreover, the complex fragmentation pattern at lower masses than the mother ion (PIC ${ }^{\{+,-\}}$) could obscure any signal of dehydrogenated species.

After annealing, bright molecules with a centered pentagonal ring structure are observed predominantly at the step edges (Figure 6a, Figure S6). Their relative abundance of $20 \%$ corresponds approximately to the abundance of cavity-down PIC before annealing (Figure S7). Hence, these bright entities after annealing are assigned as bowl-shaped dehydrogenation products, similar to previously reported observations. ${ }^{59,60}$ The major source of atomic hydrogen is dehydrogenating cavitydown molecules. Assuming that the two configurations are still present at reaction conditions, it seems likely that only the cavity-up species will become hydrogenated, because only then can the atomic hydrogen, which is located on the surface, reach the reaction sites at the bowl. These conclusions are based on the assumption that dehydrogenation of cavity-down PIC indeed occurs. However, in the unlikely case that cavity-down PIC does not show a PIC mass signal in ToF-SIMS, the absence of such signal after annealing (Figure 5) cannot serve as evidence that the bright molecules with a centered pentagonal ring structure became dehydrogenated.

PAHs may exist in planar non-Kekulé diradicaloid structures, ${ }^{51-66}$ but also in non-planar species, such as helicenes or buckybowls. ${ }^{67-70}$ That means, a closed-shell structure is being pushed to the limit of dissociation of one $\pi$ bond to generate an open-shell structure with two weakly coupled unpaired electrons within the molecule. Hence, the hydrogenated products were evaluated for potential planar non-Kekulé diradicaloid structures by theoretical means. Interestingly, both D-DFT and DMRG calculations predict for the free $\mathrm{PIC} /+2 \mathrm{H}$ a closed shell structure, but an open shell character for the $\mathrm{PIC} /+4 \mathrm{H}$ product (Figures S9, S10 \& S11). While the $\mathrm{PIC} /+2 \mathrm{H}$ triplet state is $0.3 \mathrm{eV}$ higher than the closed-shell singlet, for $\mathrm{PIC} /+4 \mathrm{H}$ the open-shell structures are favored by $0.5 \mathrm{eV}$. However, due to interaction with $\mathrm{Cu}$ surface states, the open-shell structure becomes quenched (Figure S12). Recently, it has been shown that diradicaloid structures in relatively small, planar PAHs can survive on a metal surface without being quenched by surface states. ${ }^{71}$ Therefore, the $\mathrm{PIC} /+4$ product will be tested for Kondo effect in further studies on less reactive metallic substrates such as $\mathrm{Au}(111)$.

\section{CONCLUSIONS}

The buckybowl pentaindenocorannulene engages in two different adsorbate modes on $\mathrm{Cu}(100)$, a cavity pointing up and a cavity pointing down mode, whereby the 'cavityup' mode represents the major configuration. DFT calculations and AFM height measurements strongly suggest that in this configuration the bowl is immersed into a 4-atom vacancy in the surface.

In contrast to common planarization of PAH by thermally induced dehydrogenation, ${ }^{4,11,12}$ PIC turns planar by hydrogenation and $\mathrm{C}-\mathrm{C}$ bond cleavage. In a first step, a C6 ring in the corannulene core between two indeno groups opens, and in a second step a C-C bond cleavage in the centered pentagonal ring is observed. Each step is accompanied by adding hydrogen atoms to the respective $\mathrm{C}$-atoms involved in the former $\mathrm{C}-\mathrm{C}$ bonds. These hydrogenated carbon atoms are part of pentagonal carbon rings, which suggest the possibility of open shell diradical structures. Such scenario is confirmed for the $\mathrm{PIC} / 4 \mathrm{H}$ by theoretical means for the free species. Because no deuterated species were found under backfilling the chamber with deuterium gas residual hydrogen gas as source can be excluded here. Atomic hydrogen most likely originates from dehydrogenation of bowl molecules at step edges. It is anticipated, that hydrocarbon-induced magnetization at metal-organic electrodes becomes an alternative approach towards spintronics interfaces design. 


\section{METHODS}

The experiments were performed in ultrahigh vacuum on a $\mathrm{Cu}(100)$ single crystal surface prepared by cycles of $\mathrm{Ar}^{+}$ ion sputtering and annealing. The molecules were sublimed from a crucible kept at 345 to $360^{\circ} \mathrm{C}$ with typical sublimation times ranging from 5 to $20 \mathrm{~min}$. Negative and positive ion ToF-SIMS (IONTOF, ToF-SIMS 5) spectra were recorded using a $25 \mathrm{keV}$ beam of $\mathrm{Bi}_{3}{ }^{+}$primary ions. The beam was randomly rastered over an area of $0.25 \mathrm{~mm}^{2}$. The extraction voltage was $3 \mathrm{kV}$. The pressure during preparation and measurements was below $10^{-8} \mathrm{mbar}$. The STM and nc-AFM data were recorded at $5 \mathrm{~K}$ using a qPlus sensor. The pressure in the STM/AFM chamber during preparation was around $3 \times 10^{-9} \mathrm{mbar}$. The STM images were recorded in constant current mode with the imaging parameters described in Table S1. nc-AFM images were recorded in constant height mode using an amplitude set point of $50 \mathrm{pm}$ and a bias voltage of $5 \mathrm{mV}$.

The DFT calculations have been performed using the FHIAIMS code. ${ }^{70}$ For the calculations involving the substrate, the general gradient approximation PBE potential was used. ${ }^{71}$ The gas phase calculations were performed using the hybrid potential b3lyp including electron spin.72 A light basis set was used in both cases. Van der Waals interactions were considered by employing the Tkatchenko-Scheffler method. ${ }^{73}$ The $\mathrm{Cu}(100)$ substrate was described with a $(9 \times 9)$ slab with 3 layers. The bottom layer was kept fixed and the two upper layers were allowed to relax. The Brillouin zone was described at the $\Gamma$ point. The energy and force tolerances for convergence were set to $10^{-5} \mathrm{eV}$ and $0.01 \mathrm{eV} / \AA$, respectively. The character of the singlet state wavefunctions of $\mathrm{PIC} /+2 \mathrm{H}$ and $\mathrm{PIC} /+4 \mathrm{H}$ was evaluated also by means multireference approach employing the DMRG method, ${ }^{74,75}$ in which 34 electrons were correlated in 34 orbitals. The def2-SVP basis set was used in these calculations. ${ }^{76}$ The orbitals around the Fermi level, which were used for the active space construction were obtained using the ORCA program package. ${ }^{77}$ The DMRG calculations with bond dimensions of 6000 were performed by means of the parallel MOLMPS program. ${ }^{78}$

The AFM images were simulated with the particle probe model. ${ }^{45,46}$ The parameters of the probe particle were selected to mimic a CO-tip, using a quadrupolar charge of -0.05 e ( $s$ and $p_{z}$ orbitals) with and a lateral stiffness of $0.24 \mathrm{Nm}^{-1}$. The electrostatic force was included in the probe particle model calculations using the Hartree potential calculated by DFT.

\section{ASSOCIATED CONTENT}

The Supporting Information is available free of charge on the ACS Publications website at DOI: [doi].

Experimental parameters, comparison of DFT calculations, AFM height analyses, additional ToF-SIM spectra, product statistics, additional STM and AFM images, and density of states calculation results (PDF).

\section{Notes}

The authors declare no competing financial interest .

\section{AUTHOR INFORMATION}

\section{Corresponding Author}

*E-mail: karl-heinz.ernst@empa.ch

\section{ORCHID}

Christian Wäckerlin: orcid.org/0000-0001-6587-1235

Aurelio Gallardo: orcid.org/0000-0001-6544-7637

Anaïs Mairena: orcid.org/0000-0001-7225-6222

Miloš Baljozović: orcid.org/0000-0002-2728-8142

Aleš Cahlík: orcid.org/0000-0002-3557-9521

Pavel Jelinek: orcid.org/0000-0002-5645-8542

Karl-Heinz Ernst: orcid.org/0000-0002-2077-4922

\section{ACKNOWLEDGMENT}

Support by the Swiss National Science Foundation (SNF) is gratefully acknowledged. CW thanks the SNF for a Mobility fellowship. KHE thanks the European Union for granting a Mobility Professorship. LV acknowledges support from the Czech Science Foundation (grant no. 18-18940Y). Part of this work was part of the research project RVO (61388963) of the IOCB of the Czech Academy of Sciences (D.N.). We thank Samuel Lampard and Jay Siegel for providing the PIC compound. We acknowledge support from Praemium Academie of the Academy of Science of the Czech Republic, GACR 18-09914S and CzechNanoLab Research Infrastructure supported by MEYS CR (LM2018110).

\section{Funding Sources}

University Research Priority Program LightChEC of the University of Zurich, Switzerland

Swiss National Science Foundation (R'Equip, Grants 163296, 173720 and P300P2_177755)

\section{REFERENCES}

(1) Fan, Q.; Gottfried, J. M.; Zhu, J. Surface-Catalyzed C-C Covalent Coupling Strategies toward the Synthesis of LowDimensional Carbon-Based Nanostructures. Acc. Chem. Res. 2015, 48, 2484-2494.

(2) Klappenberger, F.; Zhang, Y.-Q.; Björk, J.; Klyatskaya, S.; Ruben, M.; Barth, J. V. On-Surface Synthesis of Carbon-Based Scaffolds and Nanomaterials Using Terminal Alkynes. Acc. Chem. Res. 2015, 48, 2140-2150.

(3) Dong, L.; Liu, P. N.; Lin, N. Surface-Activated Coupling Reactions Confined on a Surface. Acc. Chem. Res. 2015, 48, 27652774.

(4) Cai, J.; Ruffieux, P.; Jaafar, R.; Bieri, M.; Braun, T.; Blankenburg, S.; Muoth, M.; Seitsonen, A. P.; Saleh, M.; Feng, X.; Müllen, K.; Fasel, R. Atomically Precise Bottom-Up Fabrication of Graphene Nanoribbons. Nature 2010, 466, 470-473.

(5) Fan, Q.; Wang, C.; Han, Y.; Zhu, J.; Hieringer, W.; Kuttner, J.; Hilt, G.; Gottfried, J. M. Surface-Assisted Organic Synthesis of 
Hyperbenzene Nanotroughs. Angew. Chem. Int. Ed. 2013, 52, 4668-4672.

(6) Xi, M.; Bent, B. E. Mechanisms of the Ullmann Coupling Reaction in Adsorbed Monolayers. J. Am. Chem. Soc. 1993, 115, 7426-7433.

(7) Grill, L.; Dyer, M.; Lafferentz, L.; Persson, M.; Peters, M. V.; Hecht, S. Nano-Architectures by Covalent Assembly of Molecular Building Blocks. Nat. Nanotech. 2007, 2, 687-691.

(8) Zuzak, R.; Castro-Esteban, J.; Brandimarte, P.; Engelund, M.; Cobas, A.; Piątkowski, P.; Kolmer, M.; Pérez, D.; Guitián, E.; Szymonski, M.; Sánchez-Portal, D.; Godlewski, S.; Peña, D. Building a 22-Ring Nanographene by Combining In-Solution and On-Surface Syntheses. Chem. Comm. 2018, 54, 10256-10259.

(9) Mairena, A.; Baljozovic, M.; Kawecki, M.; Grenader, K.; Wienke, M.; Martin, K.; Bernard, L.; Avarvari, N.; Terfort, A.; Ernst, K.-H.; Wäckerlin, C. The Fate of Bromine after TemperatureInduced Dehydrogenation of On-Surface Synthesized Bisheptahelicene. Chem. Sci. 2019, 10, 2998-3004.

(10) Mairena, A.; Wienke, M.; Martin, K.; Avarvari, N.; Terfort, A.; Ernst, K.-H.; Wäckerlin, C. Stereospecific Autocatalytic Surface Explosion Chemistry of Polycyclic Aromatic Hydrocarbons. J. Am. Chem. Soc. 2018, 140, 7705-7709.

(11) Weiss, K.; Beernink, G.; Dötz, F.; Birkner, A.; Müllen, K.; Wöll, C. Template-Mediated Synthesis of Polycyclic Aromatic Hydrocarbons: Cyclodehydrogenation and Planarization of a Hexaphenylbenzene Derivative at a Copper Surface. Angew. Chem. Int. Ed. 1999, 38, 3748-3752.

(12) Beernink, G.; Gunia, M.; Dötz, F.; Ostrom, H.; Weiss, K.; Müllen, K.; Wöll, C. Synthesis of Polycyclic Aromatic Hydrocarbons and Graphite Islands via Surface-Induced Reaction of Small Molecules. Chemphyschem 2001, 2, 317-320.

(13) Sanchez-Valencia, J. R.; Dienel, T.; Gröning, O.; Shorubalko, I.; Mueller, A.; Jansen, M.; Amsharov, K.; Ruffieux, P.; Fasel, R. Controlled Synthesis of Single-Chirality Carbon Nanotubes. Nature 2015, 512, 61-64.

(14) Talyzin, A. V.; Tsybin, Y. O.; Purcell, J. M.; Schaub, T. M.; Shulga, Y. M.; Noréus, D.; Sato, T.; Dzwilewski, A.; Sundqvist, B.; Marshall, A. G. Reaction of Hydrogen Gas with $C_{60}$ at Elevated Pressure and Temperature: Hydrogenation and Cage Fragmentation. J. Phys. Chem. A 2006, 110, 8528-8534.

(15) Talyzin, A. V.; Luzan, S.; Anoshkin, I. V.; Nasibulin, A. G.; Kauppinnen, E. I.; Dzwilewski, A.; Kreta, A.; Jamnik, J.; Hassanien, A.; Lundstedt, A.; Grennberg, $H$. Hydrogen-Driven Cage Unzipping of $\mathrm{C}_{60}$ into Nano-Graphenes. J. Phys. Chem. C 2014, 118, 6504-6513.

(16) Wu, Y.-T.; Siegel, J. S. Aromatic Molecular-Bowl Hydrocarbons: Synthetic Derivatives, Their Structures, and Physical Properties. Chem. Rev. 2006, 106, 4843-4867.

17) Tsefrikas, V. M.; Scott, L. T. Geodesic Polyarenes by Flash Vacuum Pyrolysis. Chem. Rev. 2006, 106, 4868-4884.

(18) Valenti, G.; Bruno, C.; Rapino, S.; Fiorani, A.; Jackson, E. A.; Scott, L. T.; Paolucci, F.; Marcaccio, M. Intense and Tunable Electrochemi-luminescence of Corannulene. J. Phys. Chem. C 2010, 114, 19467-19472.

(19) Bauert, T.; Zoppi, L.; Koller, G.; Siegel, J. S.; Baldridge, K. K.; Ernst, K.-H. Quadruple Anionic Buckybowls by Solid-State Chemistry of Corannulene and Cesium. J. Am. Chem. Soc. 2013, $135,12857-12860$.

(20) Ayalon, A.; Sygula, A.; Cheng, P. C.; Rabinovitz, M.; Rabideau, P. W.; Scott, L. T. Stable High-Order Molecular
Sandwiches - Hydrocarbon Polyanion Pairs with Multiple Lithium Ions Inside and Out. Science 1994, 265, 1065-1067.

21) Zabula, A. V.; Filatov, A. S.; Spisak, S. N.; Rogachev, A. Y.; Petrukhina, M. A. A Main Group Metal Sandwich: Five Lithium Cations Jammed between Two Corannulene Tetraanion Decks. Science 2011, 333, 1008-1011.

(22) Bauert, T.; Merz, L.; Bandera, D.; Parschau, M.; Siegel, J. S.; Ernst, K.-H. Building 2D Crystals from 5-Fold-Symmetric Molecules. J. Am. Chem. Soc. 2009, 131, 3460-3461.

(23) Zoppi, L.; Bauert, T.; Siegel, J. S.; Baldridge, K. K.; Ernst, K. $\mathrm{H}$. Pentagonal Tiling with Buckybowls: Pentamethylcorannulene on $\mathrm{Cu}(111)$. Phys. Chem. Chem. Phys. 2012, 14, 13365-13369.

(24) Stöckl, Q.; Bandera, D.; Kaplan, C. S.; Ernst, K.-H.; Siegel, J. S. Gear-Meshed Tiling of Surfaces with Molecular Pentagonal Stars. J. Am. Chem. Soc. 2014, 136, 606-609.

(25) Parschau, M.; Fasel, R.; Ernst, K.-H.; Gröning, O.; Brandenberger, L.; Schillinger, R.; Greber, T.; Seitsonen, A. P.; Wu, Y.-T.; Siegel, J. S. Buckybowls on Metal Surfaces: Symmetry Mismatch and Enantiomorphism of Corannulene on $\mathrm{Cu}(110)$. Angew. Chem. Int. Ed. 2007, 46, 8258-8261.

(26) Guillermet, O.; Niemi, E.; Nagarajan, S.; Bouju, X.; Martrou, D.; Gourdon, A.; Gauthier, S. Self-Assembly of Fivefold-Symmetric Molecules on a Threefold-Symmetric Surface. Angew. Chem. Int. Ed. 2009, 48, 1970-1973.

(27) Baby, A.; Lin, H.; Ravikumar, A.; Bittencourt, C.; Wegner, $\mathrm{H}$. A.; Floreano, L.; Goldoni, A.; Fratesi, G. Lattice Mismatch Drives Spatial Modulation of Corannulene Tilt on Ag(111). J. Phys. Chem. C 2018, 122, 10365-10376.

(28) Calmettes, B.; Nagarajan, S.; Gourdon, A.; Abel, M.; Porte, L.; Coratger, R. Bicomponent Supramolecular Packing in Flexible Phthalocyanine Networks. Angew. Chem. Int. Ed. 2008, 47, 69946998.

(29) Bauert, T.; Baldridge, K. K.; Siegel, J. S.; Ernst, K.-H. SurfaceAssisted Bowl-In-Bowl Stacking of Nonplanar Aromatic Hydrocarbons. Chem. Comm. 2011, 47, 7995-7997.

(30) Xiao, W.; Passerone, D.; Ruffieux, P.; Ait Mansour, K.; Gröning, O.; Tosatti, E.; Siegel, J. S.; Fasel, R. C $60 /$ Corannulene on $\mathrm{Cu}(110):$ A Surface-Supported Bistable Buckybowl-Buckyball Host-Guest System. J. Am. Chem. Soc. 2008, 130, 4767-4771.

(31) Merz, L.; Parschau, M.; Zoppi, L.; Baldridge, K. K.; Siegel, J. S.; Ernst, K.-H. Reversible Phase Transitions in a Buckybowl Monolayer. Angew. Chem. Int. Ed. 2009, 48, 1966-1969.

(32) Merz, L.; Bauert, T.; Parschau, M.; Koller, G.; Siegel, J. S.; Ernst, K.-H. Polymorph Selection in 2D Crystals by Phase Transition Blocking. Chem. Commun. (Camb.) 2009, 5871-5873.

(33) Bauert, T.; Zoppi, L.; Koller, G.; Garcia, A.; Baldridge, K. K.; Ernst, K.-H. Large Induced Interface Dipole Moments without Charge Transfer: Buckybowls on Metal Surfaces. J. Phys. Chem. Lett. 2011, 2, 2805-2809.

(34) Zoppi, L.; Garcia, A.; Baldridge, K. K. Theoretical Investigation of the Binding Process of Corannulene on a $\mathrm{Cu}(111)$ Surface. J. Phys. Chem. A 2010, 114, 8864-8872.

(35) Zoppi, L.; Stöckl, Q.; Mairena, A.; Allemann, O.; Siegel, J. S.; Baldridge, K. K.; Ernst, K.-H. Pauli Repulsion versus van der Waals: Interaction of Indenocorannulene with a $\mathrm{Cu}(111)$ Surface. J. Phys. Chem. B 2017, 122, 871-877.

(36) Stöckl, Q. S.; Wu, T.-C.; Mairena, A.; Wu, Y.-T.; Ernst, K.-H. Erecting Buckybowls onto their Edge: 2D Self-Assembly of Terphenylcorannulene on the $\mathrm{Cu}(111)$ Surface. Faraday Discuss. 2017, 204, 429-437. 
(37) Stöckl, Q. S.; Hsieh, Y.-C.; Mairena, A.; Wu, Y.-T.; Ernst, K.$\mathrm{H}$. Aggregation of $\mathrm{C}_{70}$-Fragment Buckybowls on Surfaces: $\pi-\mathrm{H}$ and $\pi-\pi$ Bonding in Bowl Up-Side-Down Ensembles. J. Am. Chem. Soc. 2016, 138, 6111-6114.

(38) Mairena, A.; Zoppi, L.; Lampart, S.; Baldridge, K. K.; Siegel, J. S.; Ernst, K. H. Fivefold Symmetry and 2D Crystallization: SelfAssembly of the Buckybowl Pentaindenocorannulene on a Cu(100) Surface Chem. Eur. J. 2019, 25, 11555-11559.

(39) Lampart, S.; Roch, L. M.; Dutta, A. K.; Wang, Y.; Warshamanage, R.; Finke, A. D.; Linden, A.; Baldridge, K. K.; Siegel, J. S. Pentaindenocorannulene: Properties, Assemblies, and $C_{60}$ Complex. Angew. Chem. Int. Ed. 2016, 55, 14648-14652.

(40) Jackson, E. A.; Steinberg, B. D.; Bancu, M.; A. Wakamiya; Scott, L. T. Pentaindenocorannulene and Tetraindenocorannulene: New Aromatic Hydrocarbon Pi Systems with Curvatures Surpassing That of $C_{60}$. J. Am. Chem. Soc. 2007, 129, 484-485.

(41) Filatov, A. S.; Scott, L. T.; Petrukhina, M. A. $\pi-\pi$ Interactions and Solid State Packing Trends of Polycyclic Aromatic Bowls in the Indenocorannulene Family: Predicting Potentially Useful Bulk Properties. Cryst. Growth Des. 2010, 10, 4607-4621.

(42) Steinberg, B. D.; Jackson, E. A.; Filatov, A. S.; Wakamiya A.; Petrukhina, M. A.; Scott, L. T. Aromatic $\pi-S y s t e m s$ More Curved Than $C_{60}$. The Complete Family of All Indenocorannulenes Synthesized by Iterative Microwave-Assisted Intramolecular Arylations. J. Am. Chem. Soc. 2009, 131, 10537-10545.

(43) Denis, P. A. Investigation of $\mathrm{H}_{2}$ Physisorption on Corannulene $\left(\mathrm{C}_{20} \mathrm{H}_{10}\right)$, Tetraindenocorannulene $\left(\mathrm{C}_{44} \mathrm{H}_{18}\right)$, Pentaindenocorannulene $\left(\mathrm{C}_{50} \mathrm{H}_{20}\right), \mathrm{C}_{60}$, and Their Nitrogen Derivatives. J. Phys. Chem. C 2008, 112, 2791-2796.

(44) Jackson, E. A.; Steinberg, B. D.; Bancu, M.; Wakamiya, A.; Scott, L. T. Pentaindenocorannulene and Tetraindenocorannulene: New Aromatic Hydrocarbon $\Pi$ Systems with Curvatures Surpassing That of $\mathrm{C}_{60}$. J. Am. Chem. Soc. 2007, $129,484-485$.

(45) Scott, L. T.; Jackson, E. A.; Zhang, Q.; Steinberg, B. D.; Bancu, M.; Li, B. A Short, Rigid, Structurally Pure Carbon Nanotube by Stepwise Chemical Synthesis. J. Am. Chem. Soc. 2012, 134, 107-110.

(46) Whalley, A. C.; Plunkett, K. N.; Gorodetsky, A. A.; Schenck, C. L.; Chiu, C.-Y.; Steigerwald, M. L.; Nuckolls, C. Bending Contorted Hexabenzocoronene Into a Bowl. Chem. Sci. 2010, 2, 132-135.

(47) a) Hapala, P.; Kichin, G.; Wagner, C.; Tautz, F. S.; Temirov, R.; Jelínek, P. Mechanism of High-Resolution STM/AFM Imaging with Functionalized Tips. Phys. Rev. B 2014, 90, 085421/1-9.

(48) Hapala, P.; Temirov, R.; Tautz, F. S.; Jelínek, P. Origin of High-Resolution IETS-STM Images of Organic Molecules with Functionalized Tips. Phys. Rev. Lett. 2014, 113, 226101/1-5.

(49) Abel, M.; Dmitriev, A.; Fasel, R.; Lin, N.; Barth, J. V.; Kern, K. Scanning Tunneling Microscopy and X-Ray Photoelectron Diffraction Investigation of $\mathrm{C}_{60}$ Films on $\mathrm{Cu}(100)$. Phys. Rev. B 2003, 67, 3100-3107.

(50) Pai, W. W.; Hsu, C.-L.; Lin, M. C.; Lin, K. C.; Tang, T. B. Structural Relaxation of Adlayers in the Presence of AdsorbateInduced Reconstruction: $C_{60} / \mathrm{Cu}(111)$. Phys. Rev. B 2004, 69, 147147.

(51) Pinardi, A. L.; Biddau, G.; van De Ruit, K.; Otero-Irurueta, G.; Gardonio, S.; Lizzit, S.; Schennach, R.; Flipse, C. F. J.; López, M. F.; Méndez, J.; Pérez, R.; Martín-Gag, J. A. Vacancy Formation on
$\mathrm{C}_{60} / \mathrm{Pt}(111)$ : Unraveling the Complex Atomistic Mechanism. Nanotechnology 2014, 25, 385602/1-13.

(52) Xiao, W.; Ernst, K.-H.; Palotás, K.; Zhang, Y.; Bruyer, E.; Peng, L.; Greber, T.; Hofer, W. A.; Scott, L. T.; Fasel, R. Microscopic Origin of Chiral Shape Induction in Achiral Crystals. Nat. Chem. 2016, 8, $326-330$.

(53) Stoltze, P. Simulation of Surface-Defects. J. Phys.: Condens. Matter 1994, 6, 9495-9517.

(54) Kürpick, U.; Rahman, T. S. Monovacancy Diffusion on $\mathrm{Ag}(100), \mathrm{Cu}(100)$, and $\mathrm{Ni}(100)$ : Prefactors and Activation Barriers. Phys. Rev. B 1999, 59, 11014-11019.

(55) Pai, W. W.; Swan, A. K.; Zhang, Z.; Wendelken, J. F. Island Diffusion and Coarsening on Metal (100) Surfaces. Phys. Rev. Lett. 1997, 79, 3210-3213.

(56) Li, J.; Lampart, S.; Siegel, J. S.; Ernst, K.-H.; Wäckerlin, C. Graphene Grown from Flat and Bowl Shaped Polycyclic Aromatic Hydrocarbons on $\mathrm{Cu}(111)$. Chemphyschem 2019, 20, 2354-2359.

(57) Fritton, M.; Duncan, D. A.; Deimel, P. S.; Rastgoo-Lahrood, A.; Allegretti, F.; Barth, J. V.; Heckl, W. M.; Björk, J.; Lackinger, M. The Role of Kinetics versus Thermodynamics in Surface-Assisted Ullmann Coupling on Gold and Silver Surfaces. J. Am. Chem. Soc. 2019, 141, 4824-4832.

(58) Ceyer, S. T. The Unique Chemistry of Hydrogen beneath the Surface: Catalytic Hydrogenation of Hydrocarbons. Acc. Chem. Res. 2001, 34, 737-744.

(59) Rim, K. T.; Siaj, M.; Xiao, S.; Myers, M.; Carpentier, V. D.; Liu, L.; Su, C.; Steigerwald, M. L.; Hybertsen, M. S.; McBreen, P. H.; Flynn, G. W.; Nuckolls, C. Forming Aromatic Hemispheres on Transition-Metal Surfaces. Angew. Chem. Int. Ed. 2007, 46, 78917895.

(60) Scott, L. T. One Step Closer to Isomerically Pure Fullerenes and Heterofullerenes: Harnessing the Potential of Catalytic Surfaces. Angew. Chem. Int. Ed. 2009, 48, 436-437.

(61) Clar, E.; Macpherson, I. A. The Significance of Kekulé Structures for the Stability of Aromatic Systems-II. Tetrahedron 1962, 18, 1411-1416.

(62) Clar E. The Aromatic Sextet. Mobile Source Emissions Including Polycyclic Organic Species. $1^{\text {st }}$ Ed.; NATO ASI Series (Series C: Mathematical and Physical Sciences); D. Reidel Publishing Company: Dordrecht, 1983; 109, 49-58.

(63) Kubo, T. Phenalenyl-Based Open-Shell Polycyclic Aromatic Hydrocarbons. The Chemical Record 2014, 15, 218-232.

(64) Konishi, A.; Kubo, T. Benzenoid Quinodimethanes. Top. Curr. Chem. 2017, 375, 1-37.

(65) Abe, M. Diradicals. Chem. Rev. 2013, 113, 7011-708.

(66) Mou, Z.; Kertesz, M. Pancake Bond Orders of a Series of $\pi$-Stacked Triangulene Radicals. Angew. Chem. Int. Ed. 2017, 56, 10188-10191.

(67) Ravat, P.; Šolomek, T.; Rickhaus, M.; Häussinger, D.; Neuburger, M.; Baumgarten, M.; Juríček, M. Cethrene: A Helically Chiral Biradicaloid Isomer of Heptazethrene. Angew. Chem. Int. Ed. 2016, 55, 1183-1186.

(68) Ravat, P.; Ribar, P.; Rickhaus, M.; Häussinger, D.; Neuburger, M.; Juríček, M. Spin-Delocalization in a Helical OpenShell Hydrocarbon. J. Org. Chem. 2016, 81, 12303-12317.

(69) Hsieh, Y.-C.; Wu, C.-F.; Chen, Y.-T.; Fang, C.-T.; Wang, C.-S.; Li, C.-H.; Chen, L.-Y.; Cheng, M.-J.; Chueh, C.-C.; Chou, P.-T.; Wu, Y.-T. 5,14-Diaryldiindeno[2,1-F:1',2'-J]Picene: A New Stable [7]Helicene with a Partial Biradical Character. J. Am. Chem. Soc. 2018, 140, 14357-14366. 
(70) Lu, R.-Q.; Wu, S.; Yang, L.-L.; Gao, W.-B.; Qu, H.; Wang, X.Y.; Chen, J.-B.; Tang, C.; Shi, H.-Y.; Cao, X.-Y. Stable DiindenoFused Corannulene Regioisomers with Open-Shell Singlet Ground States and Large Diradical Characters. Angew. Chem. Int. Ed. 2019, 58, 7600-7605.

(71) Mishra, S.; Beyer, D.; Eimre, K.; Kezilebieke, S.; Berger, R.; Gröning, O.; Pignedoli, C. A.; Müllen, K.; Liljeroth, P.; Ruffieux, P.; Feng, $X_{\text {.; }}$ Fasel, R. Topological Frustration Induces Unconventional Magnetism in a Nanographene. Nat. Nanotech. 2020, 15, 22-28.

(72) Blum, V.; Gehrke, R.; Hanke, F.; Havu, P.; Havu, V.; Ren, X.; Reuter, K.; Scheffler, M. Ab Initio Molecular Simulations with Numeric Atom-Centered Orbitals. Comput. Phys. Commun. 2009, 180, 2175-2196.

(73) Perdew, J. P.; Burke, K.; Ernzerhof, M. Generalized Gradient Approximation Made Simple. Phys. Rev. Lett., 1997, 77, 38653868.

(74) Ren, X.; Rinke, P.; Blum, V.; Wieferink, J.; Tkatchenko, A.; Sanfilippo, A.; Reuter, K.; Scheffler, M. Resolution-Of-Identity Approach to Hartree-Fock, Hybrid Density Functionals, RPA, MP2 and GW with Numeric Atom-Centered Orbital Basis Functions. New J. Phys. 2012, 14, 053020/1-55.
(75) Tkatchenko, A.; Scheffler, M. Accurate Molecular Van Der Waals Interactions from Ground-State Electron Density and FreeAtom Reference Data. Phys. Rev. Lett. 2009, 102, 073005/1-4.

(76) Chan, G. K.-L.; Sharma, S. The Density Matrix Renormalization Group in Quantum Chemistry. Annu. Rev. Phys. Chem. 2011, 62, 465-481.

(77) Szalay, S.; Pfeffer, M.; Murg, V.; Barcza, G.; Verstraete, F.; Schneider, R.; Legeza, Ö. Tensor Product Methods and Entanglement Optimization for $A b$ Initio Quantum Chemistry. Int. J. Quantum Chem. 2015, 115, 1342-1391.

(78) Weigend, F.; Ahlrichs, R. Balanced Basis Sets of Split Valence, Triple Zeta Valence and Quadruple Zeta Valence Quality for $\mathrm{H}$ to Rn: Design and Assessment of Accuracy. Phys. Chem. Chem. Phys. 2005, 7, 3297-3299.

(79) Neese, F. The ORCA Program System. WIREs Comput. Mol. Sci. 2012, 2,73-78.

(80) Brabec, J.; Brandejs, J.; Kowalski, K., Xantheas, S.; Legeza, Ö.; Veis, L. Massively Parallel Quantum Chemical Density Matrix Renormalization Group Method. 2020, 2001.04890, arXiv.org, https://arxiv.org/abs/2001.04890 (accessed 07/17/2020).

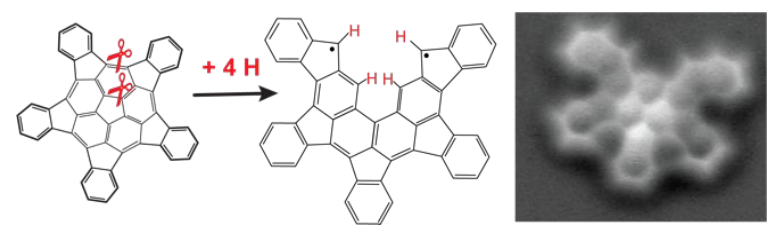

